\title{
Resveratrol targeting of AKT and p53 in glioblastoma and glioblastoma stem-like cells to suppress growth and infiltration
}

\author{
*Paul A. Clark, PhD, ${ }^{1}$ Saswati Bhattacharya, PhD, ${ }^{2,3}$ Ardem Elmayan, BS, \\ Soesiawati R. Darjatmoko, BS, ${ }^{2,3}$ Bradley A. Thuro, MD, ${ }^{2}$ Michael B. Yan, BS, ${ }^{2}$ \\ Paul R. van Ginkel, PhD, ${ }^{2}$ Arthur S. Polans, PhD, ${ }^{2-4}$ and John S. Kuo, MD, PhD ${ }^{1,4-6}$ \\ Departments of ${ }^{1}$ Neurological Surgery and ${ }^{2} \mathrm{Ophthalmology}$ and Visual Sciences, and ${ }^{3} \mathrm{McPherson}$ Eye Research Institute, \\ ${ }^{4}$ Carbone Cancer Center, and ${ }^{5} \mathrm{Center}$ for Stem Cell and Regenerative Medicine, University of Wisconsin School of Medicine and \\ Public Health, Madison, Wisconsin; and ${ }^{6}$ Department of Surgery, National University of Singapore
}

OBJECTIVE Glioblastoma multiforme (GBM) is an aggressive brain cancer with median survival of less than 2 years with current treatment. Glioblastomas exhibit extensive intratumoral and interpatient heterogeneity, suggesting that successful therapies should produce broad anticancer activities. Therefore, the natural nontoxic pleiotropic agent, resveratrol, was studied for antitumorigenic effects against GBM.

METHODS Resveratrol's effects on cell proliferation, sphere-forming ability, and invasion were tested using multiple patient-derived GBM stem-like cell (GSC) lines and established U87 glioma cells, and changes in oncogenic AKT and tumor suppressive p53 were analyzed. Resveratrol was also tested in vivo against U87 glioma flank xenografts in mice by using multiple delivery methods, including direct tumor injection. Finally, resveratrol was delivered directly to brain tissue to determine toxicity and achievable drug concentrations in the brain parenchyma.

RESULTS Resveratrol significantly inhibited proliferation in U87 glioma and multiple patient-derived GSC lines, demonstrating similar inhibitory concentrations across these phenotypically heterogeneous lines. Resveratrol also inhibited the sphere-forming ability suggesting anti-stem cell effects. Additionally, resveratrol blocked U87 glioma and GSC invasion in an in vitro Matrigel Transwell assay at doses similar to those mediating antiproliferative effects. In U87 glioma cells and GSCs, resveratrol reduced AKT phosphorylation and induced p53 expression and activation that led to transcription of downstream p53 target genes. Resveratrol administration via oral gavage or ad libitum in the water supply significantly suppressed GBM xenograft growth; intratumoral or peritumoral resveratrol injection further suppressed growth and approximated tumor regression. Intracranial resveratrol injection resulted in 100 -fold higher local drug concentration compared with intravenous delivery, and with no apparent toxicity.

CONCLUSIONS Resveratrol potently inhibited GBM and GSC growth and infiltration, acting partially via AKT deactivation and p53 induction, and suppressed glioblastoma growth in vivo. The ability of resveratrol to modulate AKT and p53, as well as reportedly many other antitumorigenic pathways, is attractive for therapy against a genetically heterogeneous tumor such as GBM. Although resveratrol exhibits low bioavailability when administered orally or intravenously, novel delivery methods such as direct injection (i.e., convection-enhanced delivery) could potentially be used to achieve and maintain therapeutic doses in the brain. Resveratrol's nontoxic nature and broad anti-GBM effects make it a compelling candidate to supplement current GBM therapies.

https://thejns.org/doi/abs/10.3171/2016.1.JNS152077

KEY WORDS brain tumor; cancer stem-like cells; glioblastoma multiforme; natural products; resveratrol; oncology

ABBREVIATIONS CED = convection-enhanced delivery; DMSO = dimethyl sulfoxide; $\mathrm{ER}$ = endoplasmic reticulum; $\mathrm{GBM}$ = glioblastoma multiforme; $\mathrm{GSC}=$ glioblastoma stem-like cell; PBS = phosphate-buffered saline; $\mathrm{PCR}=$ polymerase chain reaction.

SUBMITTED September 2, 2015. ACCEPTED January 19, 2016.

INCLUDE WHEN CITING Published online July 15, 2016; DOI: 10.3171/2016.1.JNS152077.

* Drs. Clark and Bhattacharya contributed equally to this work. 
$\mathrm{A}$ $\mathrm{N}$ estimated 22,000 new primary malignant brain tumors are diagnosed in the US each year, accounting for $1.5 \%$ of all cancer-related deaths. ${ }^{3}$ The most prevalent and aggressive malignant brain tumor is glioblastoma multiforme (GBM), also called Grade IV astrocytoma, which is a cancer of the supporting glial cells and accounts for more than 14,000 cases. ${ }^{3}$ The median survival in patients with GBMs is less than 2 years due to rapid recurrence, despite maximal surgery, temozolomide chemotherapy, and radiation. ${ }^{48}$ The subset of glioblastoma stem-like cells (GSCs) and/or other therapeutically resistant GBM cells are hypothesized to drive tumor recurrence. ${ }^{13,47}$ Therefore, therapeutic GSC targeting will be critical for improving clinical outcomes.

Glioblastomas harbor diverse genetic abnormalities, including dysregulation of receptor tyrosine kinases (PDGFR $\alpha$, EGFR), tumor suppressors (NF1, p53), and cell cycle regulatory pathways (p16, Rb) ${ }^{11}$ Recent efforts have also identified involvement of epigenetic ${ }^{36}$ and metabolic (IDH1/2) ${ }^{39,58}$ mutations in GBM. Altogether, GBMs are characterized by a complex somatic genetic landscape and redundancy in oncogenic and tumor suppressor pathways. ${ }^{11}$ This complexity suggests that specifically targeted molecular agents will likely be ineffective for improving outcomes in patients with GBM, with many such agents failing to show benefit in clinical trials. ${ }^{5}$

New therapies delivering broad anticancer effects would be desirable to treat GBM effectively. The natural plant-derived compound resveratrol (3,4',5-trihydroxytrans-stilbene) exerts multiple anticarcinogenic effects on tumor cell growth, inflammation, apoptosis, angiogenesis, invasion and/or metastasis, and sensitization to radiation and chemotherapies, ${ }^{4}$ and it inhibits growth and invasion of glioma cell lines..$^{20,25,26,31}$ Resveratrol crosses the bloodbrain barrier, ${ }^{56}$ although precise intracranial concentrations have not been established, and then exhibits pleiotropic molecular effects to alter many different signaling pathways important for GBM proliferation (i.e., nuclear factor-kB, Rb-E2F, p53, phosphatidylinositol 3-kinase/ Akt, and mitogen-activated protein kinase pathways). ${ }^{1,4}$ Some of these pathways, such as Akt, ${ }^{18,21}$ JAK/STAT, ${ }^{59}$ and Nanog, ${ }^{44}$ are also important for GSC maintenance. Importantly, resveratrol is nontoxic and exhibits virtually no serious adverse effects at doses up to $5 \mathrm{~g}$ in humans ${ }^{10}$ and could potentially be used as a nontoxic supplement to current adjuvant temozolomide chemotherapy and radiation therapy. To date, suboptimal bioavailability due to resveratrol's poor aqueous solubility and rapid metabolism to inactive products have hampered development of resveratrol-based therapies. ${ }^{8,40,43,55,57}$ However, novel delivery systems applicable to resveratrol, including nanoparticle formulations $\mathrm{s}^{37,42}$ and neurosurgical methodologies such as convection-enhanced delivery (CED),$^{53}$ are close to practical clinical applications and could potentially deliver therapeutically relevant doses of resveratrol.

In this study, we analyzed the antitumorigenic effects of resveratrol against GBM and GSCs in vitro and in vivo. Resveratrol inhibited proliferation of GBM cell lines and sphere-forming self-renewal of GSCs and blocked invasion of both GBM cells and highly invasive GSCs in vitro. Resveratrol altered multiple oncogenic and tumor suppres- sor pathways, including deactivating oncogenic Akt while stimulating p53 and the associated tumor suppressor gene network. Finally, resveratrol inhibited in vivo GBM xenograft growth through multiple routes of administration: daily oral administration, ad libitum water intake, or direct intra- and peritumoral injection. Preliminary pharmacokinetic studies in normal mouse brain demonstrated a 100 -fold increase in local resveratrol concentration using intracranial compared with intravenous delivery, without any observed toxicity. Altogether, resveratrol demonstrated broad anti-GBM activity, and as a nontoxic compound could be a valuable adjuvant therapy to improve outcomes in patients with GBMs.

\section{Methods \\ Cell Culture}

The GSCs were derived directly from GBM specimens obtained in the operating room, under a protocol approved by the University of Wisconsin-Madison's institutional review board. Glioblastoma specimens were collected anonymously from patients per the institutional review board protocol, so verifying cell lines by comparing with the original tumor was not possible. Each cell line was rigorously validated for self-renewal by neurosphere formation, multipotency, and tumor initiation (see below) before experiments were performed. Established cell cultures came from cryopreserved cell cultures ranging from passages 15 to 22 . Cells used for experiments ranged from passages 20 to 25 . The U87 glioma cell line was purchased from the American Type Culture Collection and used within 6 months of receipt without additional testing or authentication.

The GSCs were cultured under marker neutral conditions in serum-free stem cell medium as previously described. ${ }^{16,60}$ Briefly, tumor tissue was collected directly from the operating room, weighed, coarsely minced with microdissection scissors, and enzymatically dissociated (Accutase, Millipore Corp.) to single cells at $37^{\circ} \mathrm{C}$ for 20 30 minutes. The cell slurry was passed through a $40-\mu \mathrm{m}$ cell strainer and red blood cells were eliminated using a lysis buffer (Red Blood Cell Lysing Buffer, Sigma-Aldrich Co.). The final single-cell suspension was plated as suspension culture at approximately 200,000 cells $/ \mathrm{ml}$ in stem cell medium (70\% DMEM-high glucose, 30\% Ham's F12, $1 \times$ B27 supplement, $5 \mu \mathrm{g} / \mathrm{ml}$ heparin, $1 \%$ antibiotics, and $20 \mathrm{ng} / \mathrm{ml}$ each of epidermal growth factor and basic fibroblast growth factor). Cultures were passaged approximately every 10-21 days by tissue chopping $2 \times$ at $200 \mu \mathrm{m}$. Patient-specific GSC lines were isolated from primary GBM (lines 22, 33, and 44) or recurrent GBM (line 12.1). We have previously shown that these GSC lines display multilineage potential and self-renewal in cell culture, and efficiently (with as few as 100 cells) initiate GBM orthotopically in mice, growing tumors that exhibit hallmarks of human GBM, including infiltration into normal brain parenchyma. Specifically, the 44-GSC line is highly infiltrative in orthotopic xenografts ${ }^{60}$ and representative of more difficult treatment conditions in patients; therefore, resveratrol was tested against this patient-derived GSC line in most experiments. The U87 glioma cell line was 
maintained in growth medium (DMEM, $10 \%$ fetal bovine serum, and $1 \%$ antibiotics) and passaged when indicated using standard trypsin digestion (Life Technologies). The cells were maintained at $37^{\circ} \mathrm{C}$ with $5 \% \mathrm{CO}_{2}$.

\section{Proliferation Assay}

The U87 glioma cells were plated in 96-well tissue culture plates at 750 cells/well. The 44-GSCs were plated on laminin-coated 96-well tissue culture plates at 20,000 cells/well. Different dosages of resveratrol were added after overnight recovery, and viability was monitored at multiple time points using cell titer blue (Promega Corp.) according to the manufacturer's instructions. Medium was changed every other day with fresh aliquots of resveratrol. Fluorescence was measured at excitation/emission wavelengths of 560/590 nm, respectively, by using a fluorescence plate reader (Synergy Molecular Devices). ${ }^{51}$

\section{GSC Sphere-Forming Assay}

Plating densities resulting in visually near-clonogenic sphere growth for all GSC lines were optimized first. For experiments, spheres were enzymatically dissociated to single cells and incubated in 96-well plates at optimal density (500-1000 cells) in stem cell medium. After recovery overnight, resveratrol or vehicle control $(0.1 \%$ dimethyl sulfoxide [DMSO]) was added, establishing a dose-response curve. On formation of approximately $200-\mu \mathrm{m}-$ diameter spheres in control groups (2-4 weeks), the total number of spheres was manually counted within each of the culture wells.

\section{Invasion Assays}

Transwell inserts $(8-\mu \mathrm{m}$ pore polycarbonate Transwell permeable support, Millipore Corp.) were coated on the upper surface with $200 \mu \mathrm{g} / \mathrm{ml}$ of Matrigel at room temperature, followed by $5 \mu \mathrm{g} / \mathrm{ml}$ of fibronectin (Sigma-Aldrich Co.) at $4^{\circ} \mathrm{C}$ overnight on the lower surface, as previously described. ${ }^{9}$ Actively growing GSCs or U87 glioma cells were treated with Accutase or trypsin, respectively, and were washed and resuspended at $10^{6}$ cells $/ \mathrm{ml}$ in serumfree medium containing DMSO or resveratrol of desired dosages. Then, $10^{5}$ cells in $100 \mu \mathrm{l}$ of medium were carefully placed in the upper chamber. The upper and lower chambers contained the same media as the cell suspensions. After a 4-hour incubation at $37^{\circ} \mathrm{C}$, cells from the upper chamber were wiped clean and cells from the lower chamber were fixed with $4 \%$ paraformaldehyde. Next, DAPI (Life Technologies) diluted to $10 \mu \mathrm{g} / \mathrm{ml}$ in phosphate-buffered saline (PBS) was used to stain cell nuclei. Images were taken using a fluorescent microscope (Evos FL; Thermo Fisher Scientific, Inc.). Nuclei were automatically counted using ImageJ software (Wayne Ras-band, $\mathrm{NIH}$, rsbweb freeware) across multiple microscopic fields per experimental condition.

\section{Western Blot Analysis}

The GSCs or U87 glioma cells were lysed with radioimmunoprecipitation assay (RIPA) buffer supplemented with protease and phosphatase inhibitors and subsequently mixed with sodium dodecyl sulfate-containing solution. Equal amounts of protein were loaded onto $10 \%$ polyacrylamide gels, transferred to polyvinylidene difluoride membrane, and stained with antibodies. Primary antibodies to the following antigens were used: phosphorylated (ser473) Akt (clone D9E); pan-AKT (clone C67E7); phosphorylated (ser15) p53 (clone 16G8); p53 (clone 7F5) (all from Cell Signaling Technology, Inc.); and glyceraldehyde-3-phosphate dehydrogenase (GAPDH) (Bio-Rad, Inc.). Horseradish peroxidase-conjugated species-specific secondary antibodies (Jackson Immuno Research) were then used to label primary antibodies, followed by detection via a chemiluminescent substrate (ECL kit, GE Healthcare), as described previously. ${ }^{9,50}$

\section{Quantitative Real-Time Polymerase Chain Reaction}

After 24 hours of resveratrol treatment, U87 cells and GSCs were collected and total RNA was isolated using Trizol (Life Technologies). Following extraction with chloroform and addition of an equal volume of ethanol to the aqueous phase, samples were loaded onto RNeasy columns (Qiagen) and RNA was purified according to the manufacturer's instructions. First-strand cDNA was synthesized with random hexamers by using the Superscript III First Strand Synthesis System (Life Technologies). Specific primers were designed using Primer-BLAST (National Center for Biotechnology Information) and purchased from Integrated DNA Technologies. Quantitative real-time polymerase chain reaction (PCR) was performed with SYBR-Green supermix (Bio-Rad) on an iCycler (Bio-Rad) according to the manufacturer's instructions. Relative expression levels and ranges were calculated according to the comparative method (ABI Prism 7700 Sequence Detection System: Relative Quantitation of Gene Expression. User bulletin 2: revision B. PE Applied Biosystems; 2001).

\section{Tumor Xenograft Assays}

Resveratrol formulations were as follows: $125 \mu$ l of ethanol was added to $125 \mathrm{mg}$ of resveratrol, then dissolved in $5 \mathrm{ml}$ of a $10 \%$ P104 aqueous solution, and filtered through a $0.2-\mu \mathrm{m}$ syringe filter to obtain a clear solution (for intratumoral injection). The DMSO (4 ml) was added to 100 $\mathrm{mg}$ of resveratrol (for peritumoral injection). Although DMSO is a common vehicle used for intraperitoneal, peritumoral, and other routes of drug delivery, in our experience direct intratumoral injections of DMSO can result in the formation of scabs surrounding the injection site and more lethargic animals. The difference observed between intra- and peritumoral injections may be due to the extensive vasculature associated with the tumor. We find, however, that the problem associated with intratumoral drug delivery is alleviated by using ethanol and P104 as vehicle instead of DMSO.

The Animal Care and Use Committee at the University of Wisconsin-Madison approved all animal experiments. All animal caretakers and laboratory staff followed standards set by the Association for the Assessment and Accreditation of Laboratory Animal Care International (AAALAC International). For the in vivo experiments, 5- to 6-week-old female BALB/c nude mice (52 animals 
total) were purchased from Charles River Laboratories. Animals were housed in a pathogen-free isolation facility on a 12-hour light-dark cycle, with food and water provided ad libitum. Mice were each given a dorsal subcutaneous injection of $5 \times 10^{6} \mathrm{U} 87$ glioma cells suspended in $500 \mu \mathrm{l}$ of 1:1 culture medium and basement membrane matrix suspension (Matrigel, Becton Dickinson). Tumors were allowed to grow to approximately $200 \mathrm{~mm}^{3}$ before the animals were randomized into 8 groups. Group 1 (10 animals) received water containing $0.1 \mathrm{mg} / \mathrm{ml}$ resveratrol ad libitum for 18 days, whereas Group 2 (10 animals) received water ad libitum for the same period; Group 3 (10 mice) received $50 \mathrm{mg} / \mathrm{kg}$ of resveratrol in $100 \mu \mathrm{l}$ of Neobee M5 oil daily by oral gavage for 18 days, whereas Group 4 (10 mice) received Neobee M5 oil alone. Group 5 (3 mice) received 5 injections of $200 \mu \mathrm{l}$ of $5 \mathrm{mg}$ resveratrol in P104 (BASF Co.) into the tumor (intratumoral) over a period of 2 weeks, whereas Group 6 (3 mice) received 5 injections of P104 vehicle alone in a similar fashion; Group 7 (3 mice) received 5 injections of $200 \mu \mathrm{l}$ of resveratrol $(5 \mathrm{mg})$ in DMSO into the tissue adjacent to the tumor (peritumoral) over a period of 2 weeks, whereas Group 8 (3 mice) received 5 injections of DMSO alone over the same period.

Tumor size was measured twice weekly with calipers in 3 dimensions (length, width, and height), and the volume was determined by multiplying the 3 values. One day after the last dose, mice were killed and their tumors harvested, and a final tumor measurement taken in 3 dimensions using calipers. Animal protocols required that all mice be killed on the observation of symptomatic or moribund control group animals, and therefore long-term follow-up of treated animals could not be performed in this study. After euthanasia, the tumors were fixed in $10 \%$ neutral buffered formalin and processed for histological investigation. Five-micrometer sections were cut that encompassed the full circumference of the tumor and then were stained with $\mathrm{H} \& \mathrm{E}$. The outline of the tumor in each section was traced from a microscopically digitized image, and the areas of viable- and nonviable-appearing tumor were measured using ImageJ software.

The means and standard deviations of the tumor volume in each group were calculated. Statistical differences between each treatment group and the respective control group were determined using an unpaired 2-tailed t-test; $p$ values less than 0.05 were considered significant.

\section{Resveratrol Brain Pharmacokinetic Analysis}

Resveratrol was dissolved in PBS at $100 \mu \mathrm{g} / \mathrm{ml}$, which is approximately maximum solubility. For intravenous delivery, the tails of ICR outbred mice ( 9 animals) were first submerged in warm $\left(30^{\circ} \mathrm{C}-35^{\circ} \mathrm{C}\right)$ water to stimulate vein dilation, and then $100 \mu \mathrm{l}$ of resveratrol solution was slowly injected into the tail vein.

For intracranial delivery, using a Hamilton syringe, 10 $\mu l$ of the resveratrol solution was stereotactically injected into the right striatum of anesthetized ICR outbred mice (9 animals) at $1 \mu \mathrm{l} / \mathrm{min}$ at the following coordinates referenced from bregma: $0 \mathrm{~mm}$ anteroposterior, $+2.5 \mathrm{~mm}$ mediolateral, and $-3.5 \mathrm{~mm}$ dorsoventral. ${ }^{16,60}$

In initial experiments, mice were observed for 1 hour for toxic effects. After verification that there were no toxic effects, an additional cohort of mice was killed at 5, 30, and 60 minutes ( 3 mice per time point) for a pharmacokinetic analysis. Mice were killed at each time point by exsanguination and perfused with PBS. The brain was then rapidly removed, weighed, and frozen in liquid nitrogen.

For pharmacokinetic analysis, brains were extracted with 3 volumes of PBS using 30 strokes of a Dounce (type A pestle) homogenizer, and $55 \mu l$ of each extract was then transferred to a 500- $\mu \mathrm{l}$ amber microcentrifuge tube. To construct calibration curves, extracts from untreated brains were spiked with $2.2 \mu \mathrm{l}$ of serial dilutions of resveratrol dissolved in $100 \%$ acetonitrile. Extracts from treated and untreated brains were then transferred onto Ostro plates (Waters Corp.), triturated, and incubated for approximately 2 minutes with occasional shaking. Additionally, $150 \mu \mathrm{l}$ of acetonitrile/1\% acetic acid was spiked with an internal standard, Naproxen D3. The resulting samples were run through a CSH-C18 column (Thermo Fisher Scientific, Inc.), transferred to Waters vials, and analyzed using the LC/MS/MS system (Agilent 1100 LCMSD quadrupole SL). Data were analyzed and compared with internal standards to obtain mass concentrations (in $\mu \mathrm{g} / \mathrm{g}$ ) of resveratrol in whole brain.

For intravenous delivery, resveratrol whole-brain molar concentration (in $\mu \mathrm{M}$ ) was approximated using a value for brain density of $1.081 \mathrm{~g} / \mathrm{ml}^{7}$ For intracranial delivery, local brain molar concentrations were approximated from whole-brain total drug mass by using CED parameters reported in the literature. A volume distribution $\left(\mathrm{V}_{\mathrm{d}}\right)$ to volume injected $\left(\mathrm{V}_{\mathrm{i}}\right)$ ratio of $5.23 \pm 1.67^{33}$ was used to calculate the molar concentration of resveratrol at the infusion site. This $\mathrm{V}_{\mathrm{d}} / \mathrm{V}_{\mathrm{i}}$ ratio is an experimentally derived value for CED that uses a $1 \mu \mathrm{l} / \mathrm{min}$ flow rate into nonhuman primate brain. ${ }^{33}$

The means and standard errors for mass and molar concentration in each group were also calculated.

\section{Results}

\section{Resveratrol Inhibits Glioma Cell and GSC Proliferation In Vitro}

Resveratrol's antiproliferative effects on GBM were investigated by determining dose-response growth curves in cell culture. Administration of resveratrol significantly inhibited U87 glioma cell proliferation compared with vehicle control (Fig. 1A), with a measured $\mathrm{IC}_{50}$ (half maximal inhibitory concentration) of $20 \mu \mathrm{M}$ on Day 5 of drug exposure. In parallel experiments, resveratrol also inhibited GSC proliferation (Fig. 1B). Similar effects were observed for GSC self-renewal and proliferation in which a sphereforming assay was used. Compared with DMSO vehicle control, addition of resveratrol (doses from 5 to $50 \mu \mathrm{M}$ ) resulted in more than $50 \%$ inhibition of sphere formation in 4 independent patient-derived GSC lines $(12.1,22,33$, and 44) (Fig. 1C).

\section{Resveratrol Inhibits GBM Cell Migration In Vitro}

Tumor cell infiltration into normal brain parenchyma is a hallmark of GBM, preventing complete surgical extirpation and limiting the effectiveness of adjuvant radiation and chemotherapy. ${ }^{32}$ Resveratrol inhibition of GBM cell 

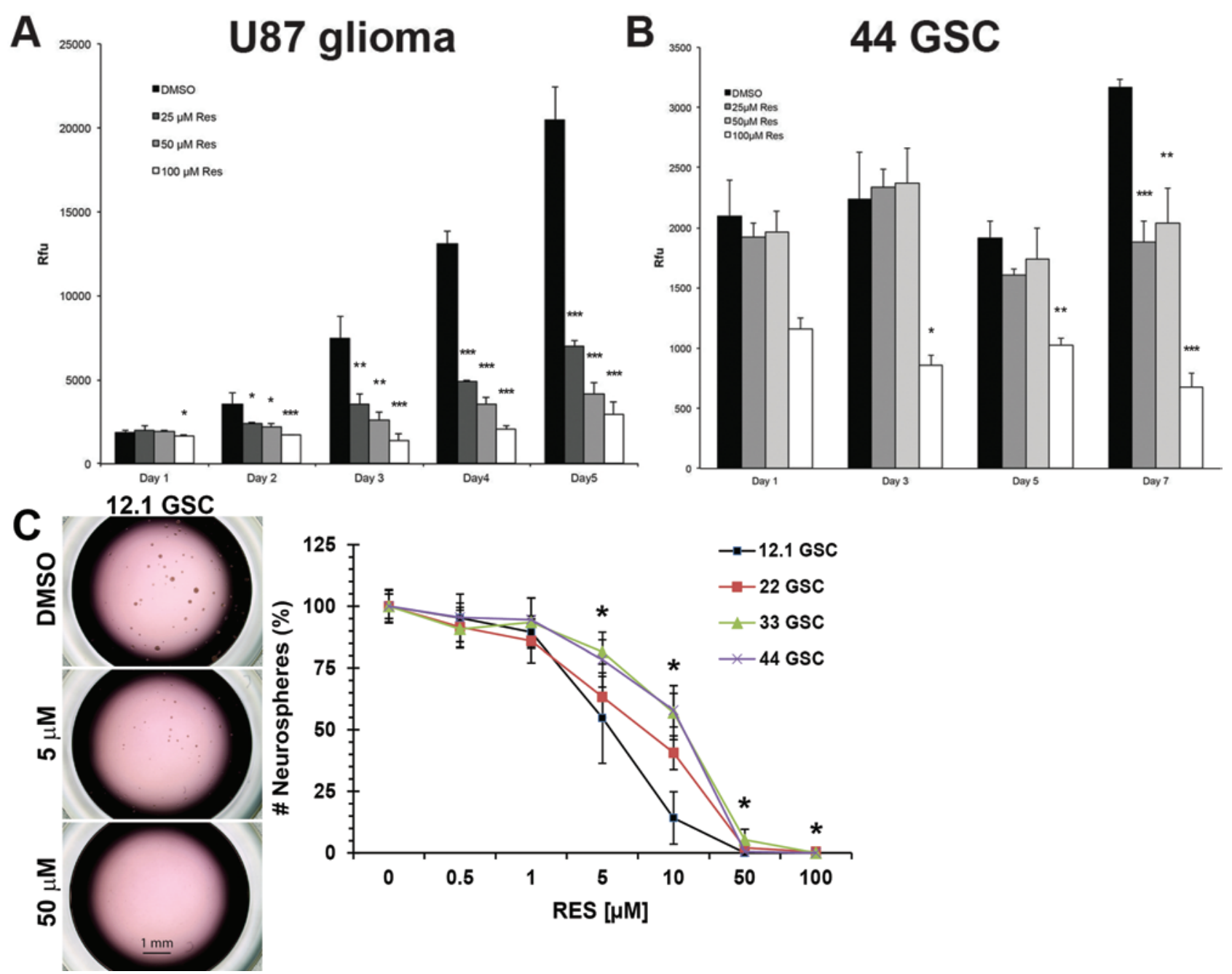

FIG. 1. Resveratrol inhibits the growth of GBM cells and GSCs. Decreased U87 glioma cell (A) and 44-GSC (B) proliferation after resveratrol treatment compared with vehicle control (DMSO) $\left({ }^{*} p \leq 0.05 ;{ }^{* *} p \leq 0.01 ;{ }^{* * *} p \leq 0.001\right.$ using Student's 2-tailed t-test, $n=$ 3 in each of 3 independent experiments). Likewise, as little as $5 \mu \mathrm{M}$ resveratrol inhibited sphere formation (C) in multiple patientderived GSC lines compared with the vehicle control ( ${ }^{*} p \leq 0.05$ compared with $0 \mu \mathrm{M}$ resveratrol [RES] by ANOVA followed by post hoc Tukey test, $n=3$ in each of 3 independent experiments). Values represent the mean $\pm S D$. Res $=$ resveratrol; Rfu $=$ relative fluorescence units.

invasion was tested using a Transwell assay with Matrigel substrate. Four hours of exposure to as little as $5 \mu \mathrm{M}$ of resveratrol significantly decreased U87 glioma cell invasion compared with the DMSO control (Fig. 2A and B; $\mathrm{p}<0.05, \mathrm{n}=3$ in each of 3 independent experiments), with greater than $75 \%$ inhibition at resveratrol doses of 50 $\mu \mathrm{M}$ and higher (Fig. 2B). Implantation of the highly invasive 44-GSC line results in orthotopic tumor xenografts throughout most of the brain parenchyma. ${ }^{60}$ Notably, 44GSCs were similarly inhibited by resveratrol in the Matrigel invasion assay cited above, as compared with vehicle controls (Fig. 2C; $\mathrm{p}<0.05, \mathrm{n}=3$ in each of 3 independent experiments).

\section{Resveratrol Affects AKT and p53 Signaling Pathways}

Resveratrol has pleiotropic effects that alter many cellular signaling pathways, ${ }^{1}$ including core oncogenic pathways such as AKT and p53 mechanisms involved in
GBM growth, survival, and invasion..$^{12}$ After resveratrol or DMSO vehicle treatment, U87 glioma cells and 44-GSCs were processed for Western blot analysis. Activation of AKT, tested via ser473 phosphorylation, was reduced in a dose-dependent manner in U87 glioma cells treated with resveratrol (Fig. 3A, upper). Resveratrol treatment also decreased AKT phosphorylation in 44-GSCs (Fig. 3A, lower). There were no discernable changes in total AKT protein levels.

To further test the involvement of AKT in GBM cell invasion, U87 glioma cells were incubated with triciribine, an AKT inhibitor, and a Transwell migration assay with Matrigel was performed. Triciribine exposure up to 24 hours did not change U87 glioma cell viability (Fig. $3 \mathrm{~B})$, but inhibited U87 glioma cell invasion by greater than $80 \%$ within 4 hours of treatment (Fig. 3C). The combination of resveratrol and triciribine inhibited cell invasion to a larger degree than either compound alone (Fig. 3C). 

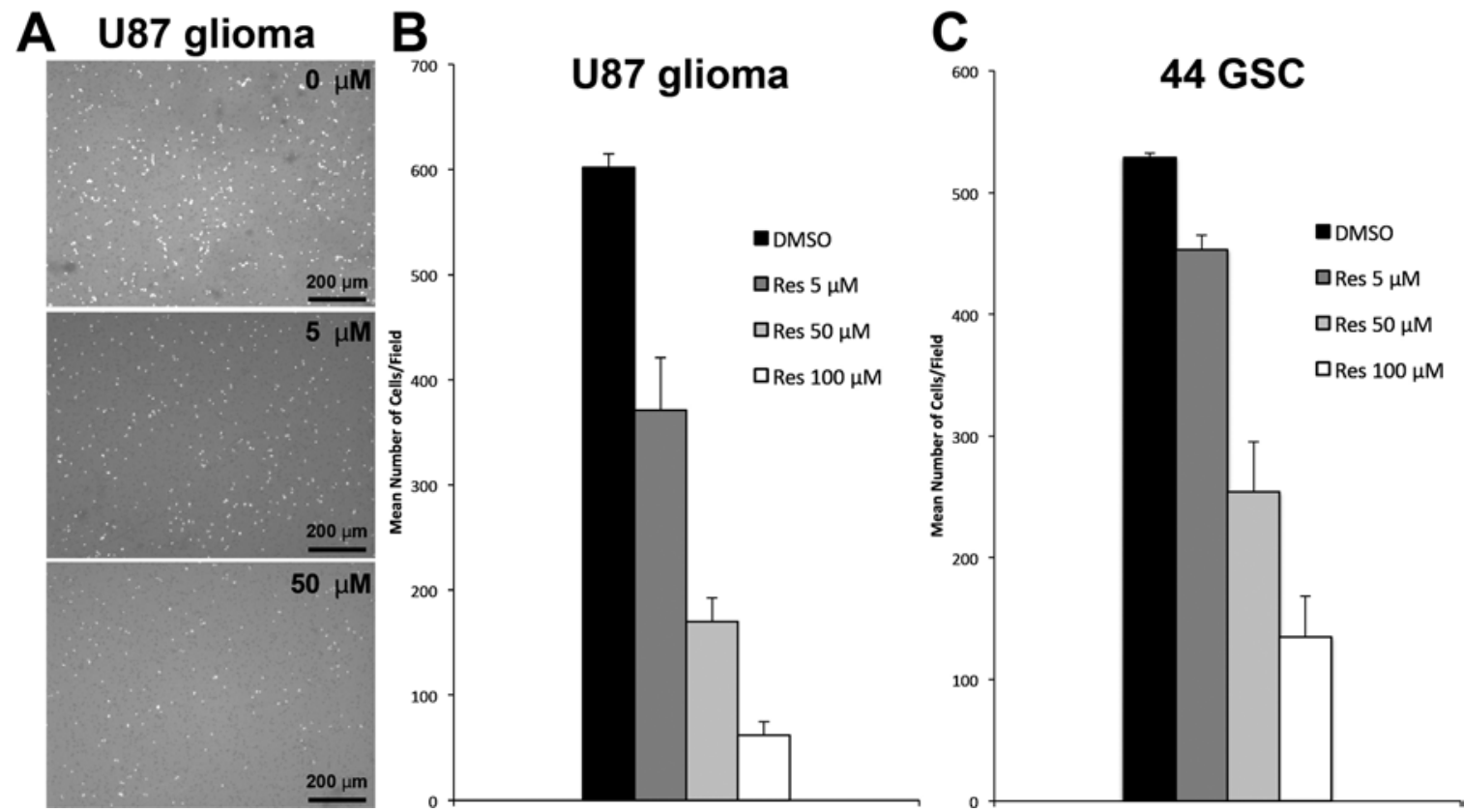

FIG. 2. Resveratrol inhibits tumor cell invasion in a Matrigel Transwell assay. A: U87 glioma cell invasion as a function of resveratrol concentration; DAPI nuclear stain: white. B: U87 glioma cell line invasion; $p<0.05, n=3$ in each of 3 independent experiments. C: $44-G S C$ invasion; $p<0.05, n=3$ in each of 3 independent experiments. Values represent the mean \pm SD.

By regulating expression of diverse downstream target genes, p53 can induce cell cycle arrest and apoptosis, contributing to the inhibition of glioma cell growth, as shown in Fig. 1. To test this possibility, U87 glioma cells and 44-GSCs were treated with resveratrol and Western blot analysis was performed using antibodies specific to p53 and phosphorylated (ser15) p53. Compared with vehicle controls, resveratrol treatment increased p53 expression and, concomitantly, the levels of phosphorylated p53 in U87 glioma cells (Fig. 4A, upper) and GSCs (Fig. 4A, lower). Resveratrol induction of p53 in U87 glioma cells was dependent on calcium (Fig. 4B, upper). Preincubation with BAPTA (a cell-permeable calcium chelator) blocked resveratrol-induced p53 expression and phosphorylation. This finding is consistent with previous reports that intracellular calcium increased after exposure of tumor cells to resveratrol. ${ }^{43}$ However, the resveratrol-induced increase of p53 expression in 44-GSCs was independent of calcium (Fig. 4B, lower). To further verify that resveratrol induces the expression and phosphorylation of p53, quantitative PCR was used to measure changes in expression of p53dependent downstream genes. As shown in Fig. 4C, resveratrol treatment of U87 glioma cells led to increased expression of Bax, Pig8, and TP53INP. Increased expression of these and additional p53-dependent target genes was observed in 44-GSCs treated with resveratrol (Fig. 4D).

\section{Resveratrol Reduces Tumor Growth In Vivo}

The antitumorigenic effects of resveratrol were tested in vivo by using a U87 glioma xenograft model. Tumor cells implanted in the dorsal flanks of immune-deficient mice formed tumor xenografts of approximately $200 \mathrm{~mm}^{3}$ after 14-21 days. Different routes of resveratrol administration were tested to measure therapeutic efficacy and to detect any toxicity. As dictated by the animal protocol, when control animals became symptomatic or moribund, all animals were killed; treated animals therefore could not be followed for long-term survival.

In the first experiment, resveratrol was administered ad libitum through the drinking water supply. Resveratrol has limited solubility of approximately $100 \mu \mathrm{g} / \mathrm{ml}$ in aqueous solutions. Mice used in this study consumed approximately $5 \mathrm{ml}$ of fluid/day, and thereby attained a daily intake of approximately $500 \mu \mathrm{g}$ of resveratrol or a dose equivalent to $25 \mathrm{mg} / \mathrm{kg} / \mathrm{day}$. In contrast to dosing via oral gavage, ad libitum consumption of water that contains resveratrol occurs over the full 24 hours of each day. Administration of resveratrol in the water supply resulted in significantly smaller average tumor volumes in resveratrol-treated animals compared with xenografts in control animals ( $\mathrm{p}=$ 0.01 ). Significantly reduced tumor volumes were observed with resveratrol administration compared with vehicletreated animals as early as 7 days and continued until euthanasia at 18 days. The average tumor volume in the resveratrol group at the end of the experiment was $916 \pm 94$ $\mathrm{mm}^{3}$ versus $1502 \pm 173 \mathrm{~mm}^{3}$ for the control group, or approximately a $40 \%$ inhibition of tumor growth at 18 days posttreatment (Fig. 5A).

For the second delivery route, a single daily delivery of resveratrol by oral gavage consisted of approximately 1 $\mathrm{mg} / \mathrm{mouse}$, equivalent to a $50 \mathrm{mg} / \mathrm{kg} /$ day dose, or roughly twice the amount of resveratrol delivered via the drinking water regimen in the first experiment. With the oral gavage treatment protocol, the average tumor volume of animals treated with resveratrol also was significantly smaller than the tumor volume of animals in the control group ( $\mathrm{p}=$ 0.04 ). The average tumor volume in the treatment group was $896 \pm 167 \mathrm{~mm}^{3}$ compared with $1435 \pm 182 \mathrm{~mm}^{3}$ for 

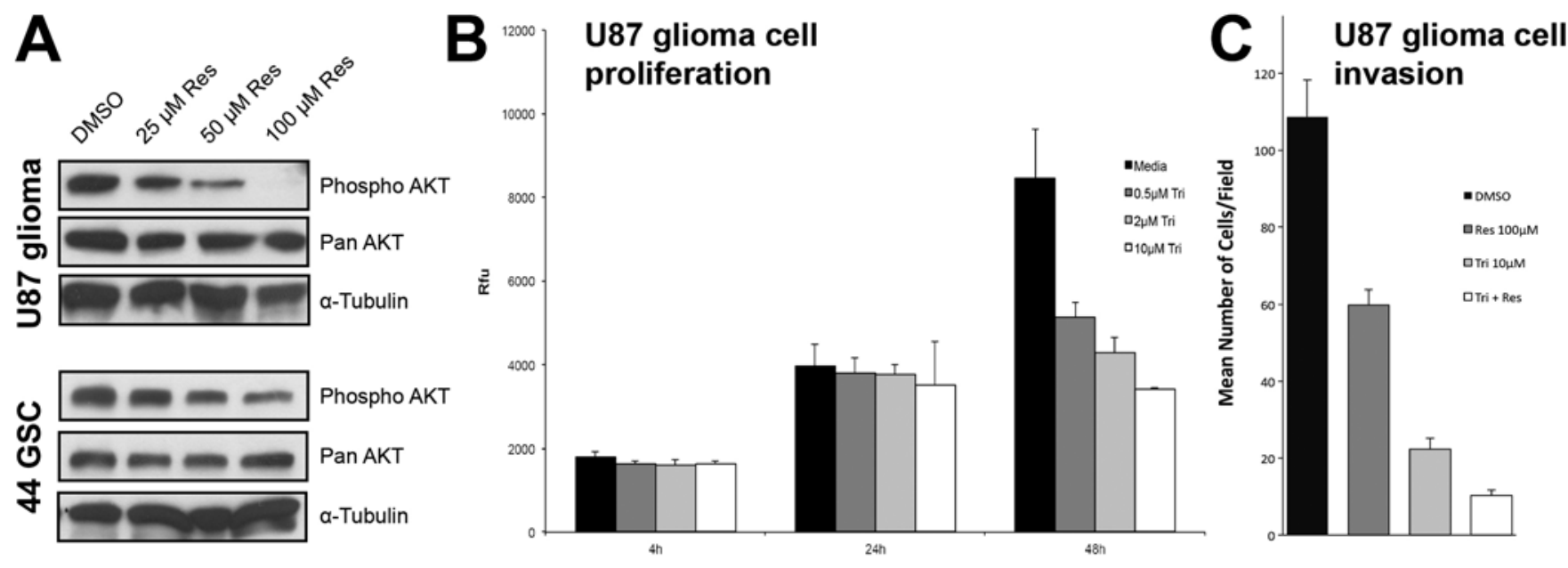

FIG. 3. Resveratrol decreases AKT activity in GBM cells and GSCs. A: Resveratrol treatment resulted in reduced AKT phosphorylation (ser473) in U87 glioma cells (upper panel) and in the 44-GSC line (lower panel), 48 hours posttreatment, while minimally affecting total AKT protein. B: Triciribine, a specific AKT inhibitor, did not affect U87 glioma cell growth up to 24 hours posttreatment, although (C) it significantly suppressed migration as early as 4 hours after treatment, compared with vehicle controls $(p<$ $0.05, n=3$ in each of 3 independent experiments), and demonstrated synergistic antiinvasion effects with resveratrol $(p<0.05, n=$ 3 in each of 3 independent experiments). Values represent the mean \pm SD. Tri $=$ triciribine.

the control group, or a $39 \%$ inhibition of tumor growth by Day 18 posttreatment.

The bioavailability of resveratrol can be increased by direct injection, thus avoiding limited uptake in the stomach and gastrointestinal tract as well as rapid metabolism in the gut and liver. ${ }^{51}$ As shown in Fig. 5B-D, the intratumoral injection of resveratrol decreased tumor volume by $60 \%$ compared with tumors injected with vehicle alone $(\mathrm{p}$ $=0.03$ ). Peritumoral injection of resveratrol had a comparable effect, decreasing tumor volume by $56 \%$ compared with the vehicle control. Subsequent histological analysis of the tumors obtained at necropsy revealed that approximately $25 \%$ of the tumor volume consisted of necrotic cells (Fig. 5B and C). There was no statistically significant difference between necrotic areas in tumors obtained from control or resveratrol-treated mice $(p=0.29)$. Even at these higher doses of resveratrol attained by direct injection, there were no adverse effects to vital organs observed on histological examination.

The ability to deliver resveratrol to the normal brain parenchyma was also explored using multiple delivery mechanisms. After intravenous injection, resveratrol was detectable in brain tissue after 5 minutes $(0.027 \pm 0.0050$ $\mu \mathrm{g} / \mathrm{g}, 0.13 \pm 0.024 \mu \mathrm{M}$; Table 1) but undetectable at 30 and 60 minutes. Using intracranial delivery, however, local resveratrol concentrations were increased approximately 100 -fold after 5 minutes $(2.8 \pm 0.20 \mu \mathrm{g} / \mathrm{g}, 13 \pm 0.94 \mu \mathrm{M}$; Table 1) and remained detectable for up to 60 minutes (30 minutes: $2.4 \pm 0.71 \mu \mathrm{g} / \mathrm{g}, 11 \pm 3.4 \mu \mathrm{M} ; 60$ minutes: $1.6 \pm$ $0.15 \mu \mathrm{g} / \mathrm{g}, 7.6 \pm 0.72 \mu \mathrm{M})$. No adverse side effects were observed up to 1 hour following intracranial delivery.

\section{Discussion}

There is considerable interest in using the nontoxic plant polyphenol compound resveratrol as a potential cancer therapeutic agent. ${ }^{20,22,42}$ It exhibits antitumorigenic activity against a broad range of cancers by modulating diverse oncogenic and tumor suppressor pathways, including proliferation, apoptosis, autophagy, migration, angiogenesis, and inflammation. ${ }^{1}$ In other cancers resveratrol has also been demonstrated to activate the intrinsic apoptotic pathway, ${ }^{51}$ an endoplasmic reticulum (ER) stress response, ${ }^{38}$ and a family of calcium-dependent cysteine proteases, ${ }^{43}$ thereby causing tumor cell death and improving cancer control..$^{29}$

In this study, we demonstrate that resveratrol induces widespread anti-GBM and anti-GSC effects by deactivating oncogenic AKT and activating the tumor suppressor p53 gene network, and inhibiting GBM's hallmarks of cell proliferation and infiltration. Resveratrol's broad antiGBM effects are very desirable due to an extensive landscape of tumor genetic aberrations ${ }^{11}$ and a large number of mutated or abnormal cancer pathways resulting in tumor heterogeneity, ${ }^{11,12}$ as well as intrinsic and rapidly acquired resistances of GBM cells and GSCs. ${ }^{6,13,16,30}$ Additionally,

TABLE 1. Brain concentrations of resveratrol*

\begin{tabular}{|c|c|c|c|}
\hline $\begin{array}{l}\text { Delivery } \\
\text { Route }\end{array}$ & $\begin{array}{l}\text { Time } \\
(\min ) \dagger\end{array}$ & $\begin{array}{l}\text { Drug Mass Concentration } \\
(\mu \mathrm{g} / \mathrm{g})\end{array}$ & $\begin{array}{c}\text { Drug Molar } \\
\text { Concentration }(\mu \mathrm{M}) \ddagger\end{array}$ \\
\hline \multirow[t]{3}{*}{ IC } & 5 & $2.8 \pm 0.20$ & $13 \pm 0.94$ \\
\hline & 30 & $2.4 \pm 0.71$ & $11 \pm 3.4$ \\
\hline & 60 & $1.6 \pm 0.15$ & $7.6 \pm 0.72$ \\
\hline \multirow[t]{3}{*}{ IV } & 5 & $0.027 \pm 0.0050$ & $0.13 \pm 0.024$ \\
\hline & 30 & Undetectable & Undetectable \\
\hline & 60 & Undetectable & Undetectable \\
\hline \multicolumn{4}{|c|}{$\begin{array}{l}\text { IC = intracranial; IV = intravenous (tail vein). } \\
\text { * Values are expressed as the mean } \pm \mathrm{SE} . \\
\dagger \text { Three mice per time point. } \\
\text { ‡ Resveratrol molar concentrations are whole-brain values for intravenous } \\
\text { delivery and localized concentration for intracranial infusion, calculated as } \\
\text { described in Methods. }\end{array}$} \\
\hline
\end{tabular}



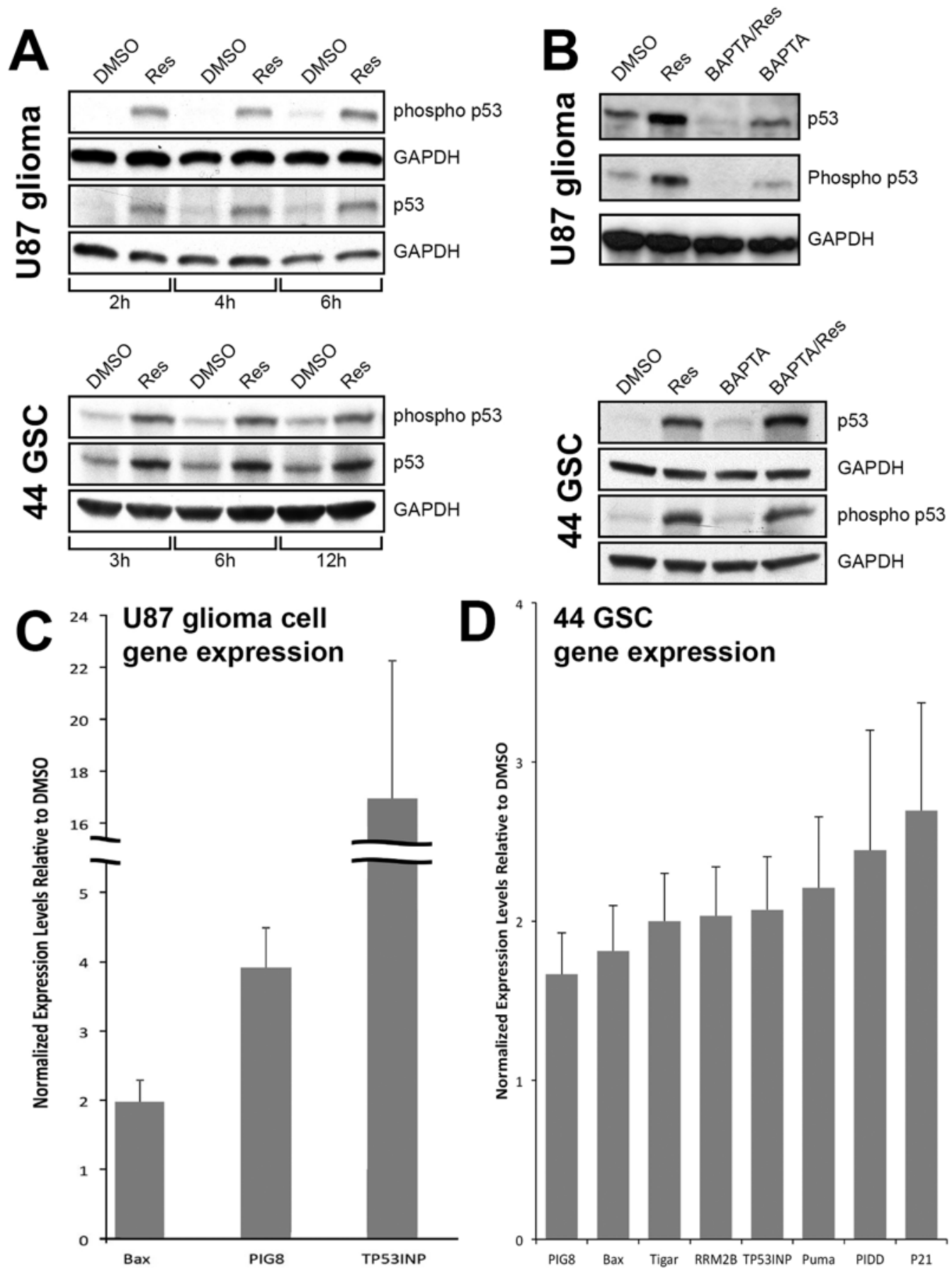

FIG. 4. Resveratrol activates $p 53$ and p53 pathway genes. A: Administration of $100 \mu \mathrm{M}$ resveratrol to U87 glioma cells (upper panel) or 44-GSCs (lower panel) increased expression and phosphorylation of p53 tumor suppressor protein. B: Activation of p53 was reduced by coadministration of a calcium chelator (BAPTA) in U87 glioma cells (upper panel), but not in 44-GSCs (lower panel). Resveratrol activation of p53 in U87 cells (C) and 44-GSCs (D) resulted in expression of multiple downstream genes of the p53 suppressor network, compared with vehicle control and detected by quantitative PCR. Data are normalized and therefore unitless. GAPDH = glyceraldehyde-3-phosphate dehydrogenase.

median survival is poor despite the current clinical treatment of maximal safe resection followed by adjuvant radiation and temozolomide chemotherapy, ${ }^{48}$ a relatively toxic regimen for patients. Resveratrol was demonstrably shown to be nontoxic, with even up to 5-g doses showing no adverse side effects in humans $;{ }^{10}$ therefore it is a good candidate to supplement current treatments. Filippi-Chiela and colleagues recently reported in vitro studies showing resveratrol's synergy with temozolomide, the current clinical GBM chemotherapy, to cause mitotic catastrophe in tumor cells. ${ }^{19}$ In addition, the ability of resveratrol to target and reduce the therapeutically resistant GSC subpopu- 

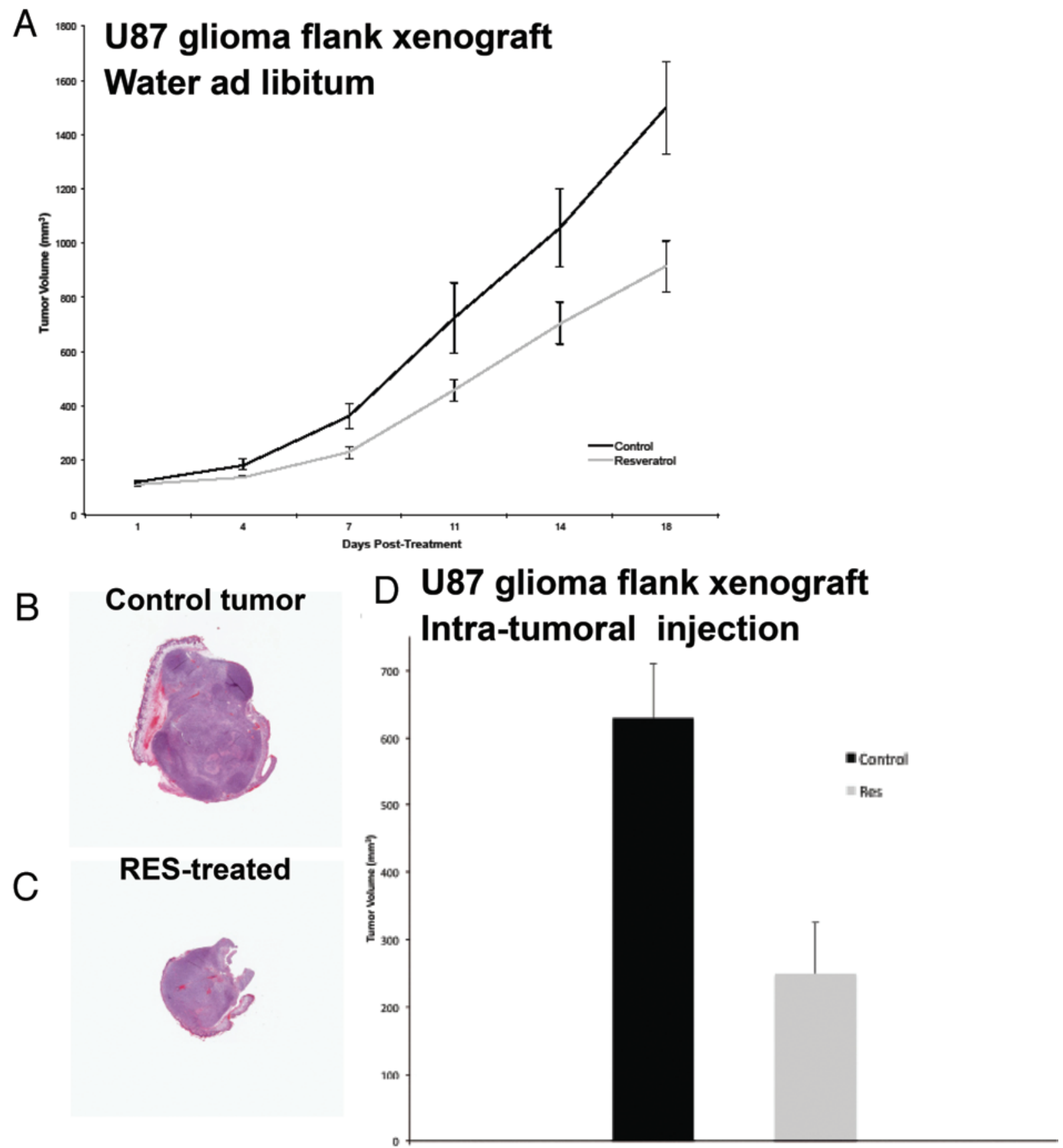

FIG. 5. Resveratrol inhibits U87 xenograft growth. A: Resveratrol administered in water ad libitum to mice harboring U87 flank xenografts resulted in significantly reduced tumor growth compared with vehicle-treated controls $(p<0.05 ; n=10$ mice per group). Similar results were obtained with intragastric delivery of resveratrol; see Results. B and C: Photomicrographs of sections of mouse flank xenograft tumors stained with $\mathrm{H} \& \mathrm{E}$, both with the same original magnification. Direct intratumoral injection of resveratrol (C) significantly decreased tumor volume in mice harboring U87 flank xenografts, compared with vehicle controls (B). D: Bar graph presenting the results depicted in panels $B$ and $C(p<0.05 ; n=3$ mice per group). Values represent the mean \pm SD.

lation, which has been shown in this study and by other groups, ${ }^{44,59}$ could also improve GBM outcomes. ${ }^{29}$ Taken together, there is compelling evidence for combining resveratrol with standard GBM treatments.

Resveratrol inhibition of the growth of GBM cells and GSCs was first demonstrated against the U87 glioma cell line and 4 independent patient-derived GSC lines isolated via marker-neutral stem cell culture. ${ }^{16,60}$ Initial viability assays suggested that resveratrol may affect GSCs less than established U87 cells, which is not surprising because GSCs are notoriously resistant to many commonly used therapies. ${ }^{6,30}$ However, the effect of resveratrol on cell viability, as shown in Fig. 1, is a composite of antiproliferative and proapoptotic events. As can be seen by comparing 
the data in Fig. 1A and B, the GSCs have a much slower growth rate, and therefore the antiproliferative effects of resveratrol are not as evident until Day 7; much later than that observed for the faster-growing U87 glioma cells. In contrast to these findings, in the longer sphere-forming assay (2-4 weeks) compared with the proliferation assay (5-7 days), the GSCs demonstrated similar drug sensitivity, which suggests anti-stem cell effects of resveratrol that may help with clinical long-term control of glioblastoma. The fact that resveratrol has less of an impact on the levels of AKT phosphorylation in GSCs (Fig. 3) during the shorter time line of the experiment correlates with the results obtained in the viability assays comparing GSCs and U87 cells. Additionally, some differences in resveratrol sensitivity were observed among GSC lines (Fig. 1C), probably due to intertumor heterogeneity of patient-derived GSCs, as has been described..$^{5,60}$

Interestingly, the resveratrol-sensitive GSC lines in this study show increased stem cell marker expression, result in less invasive orthotopic xenografts, and are positive for the oligodendroglial marker 2',3'-cyclic nucleotide 3'-phosphodiesterase (CNP), compared with other GSC lines with more invasive orthotopic xenograft phenotypes and high glial fibrillary acidic protein expression. ${ }^{60}$ The "proneural" class $^{23,41}$ shares attributes with the $\mathrm{CNP}^{+}$GSC class, such as increased stem cell gene and protein expression and less invasive orthotopic xenograft growth. Therefore, resveratrol might be used to selectively target the proneural GBM subtype that is known to be relatively resistant to current treatments. ${ }^{28,52}$ Although less sensitive to resveratrol's antiproliferative effects than the 12.1- and 22-GSC lines, the 44-GSC line was sensitive to the antiinvasive effects of resveratrol (Fig. 2), demonstrating resveratrol's utility in the broad inhibition of multiple tumorigenic processes in this molecularly heterogeneous cancer.

The specific molecular mechanism(s) underlying resveratrol's anti-GBM activities is still being elucidated. In this study, we demonstrated inactivation of AKT and activation of the p53 tumor suppressor pathway. A resveratrolmediated decrease in and inactivation of AKT protein has been demonstrated in glioma cell lines, resulting in decreased proliferation, increased apoptosis, and decreased migration. ${ }^{25,26}$ In this study, resveratrol decreased AKT phosphorylation at ser473 in both GBM cells and GSCs while minimally affecting total AKT protein levels. The AKT oncogene specifically regulates infiltration into normal brain parenchyma ${ }^{34}$ and promotes maintenance of the GSC subpopulation. ${ }^{18,21}$ It is important to note that panAKT protein assays were done in this study, and individual AKT isoforms were not tested. Some AKT isoformspecific effects have been reported in glioblastoma. ${ }^{14,35}$

Our results showing resveratrol activation of the p53 tumor suppression network are consistent with other studies. ${ }^{44}$ The U87 glioma cell line used in this study exhibits genetically wild-type p53, ${ }^{19}$ whereas p53 genotyping of the 44-GSC line is ongoing. Wild-type p53 is not always crucial to elicit a resveratrol response because some p53 mutant lines (i.e., U138) also display resveratrol sensitivity, ${ }^{19}$ due to multifaceted antiproliferative and proapoptotic effects of resveratrol, whereas others do not (i.e., LN-18). ${ }^{46}$ Serine-15 phosphorylation of p53 leads to decreased af- finity for the negative regulator $\mathrm{Mdm} 2$, and increases p53 protein stability. In addition, it promotes nuclear retention of p53 and it promotes recruitment of transcriptional coactivators of p53 target genes. We demonstrated that resveratrol activates transcription of several key downstream p53 target genes such as TP53INP1, an alternatively spliced gene that encodes 2 nuclear protein isoforms (TP53INP $\alpha$ and TP53INP1 $\beta$ ). When overexpressed, both isoforms induce cell cycle arrest in G1 and enhance p53mediated apoptosis. Another p53-activated gene is EI24/ PIG8, a novel ER-localized Bcl-2-binding protein that may contribute to apoptosis by modulating the activity and/or function of Bcl-2 in the ER. Also, EI24/PIG8 may serve to prevent tumor spreading, consistent with its suspected role as a tumor suppressor. Bax is a proapoptotic member of the Bcl-2 family that is thought to activate the mitochondrial voltage-dependent anion channel that is also activated by p53. Other studies have shown that resveratrol activates the mitochondrial or intrinsic apoptotic pathway leading to cytochrome c release and the eventual activation of caspase- $3 .{ }^{43,51}$

Sato et al. demonstrated resveratrol-induced p53 activation results in proteosomal degradation of Nanog, a transcription factor that maintains stem-like identity, and loss of stemness in GSCs. ${ }^{44}$ Other groups have shown that resveratrol regulation of STAT3 and related genes suppresses tumorigenicity and induces GSC differentiation. ${ }^{59}$ Resveratrol has also repeatedly been demonstrated to alter organism and cellular metabolism, acting as a mimetic of calorie restriction. ${ }^{15}$ Dysregulated metabolic function, such as in lipogenesis ${ }^{24}$ or through isocitrate dehydrogenase (IDH) mutation, ${ }^{39,59}$ is now established in GBM tumorigenesis. Although not tested in this study, resveratrol correction of abnormal metabolism in GBM cells and GSCs could be another potential mechanism of its antitumorigenic effect. Overall, resveratrol exerts pleiotropic molecular effects against cancer, ${ }^{1}$ suggesting a general upstream molecular mechanism with broad downstream effects that could be advantageous in cancers like GBM that have an extensive mutational and abnormal genetic landscape. ${ }^{11}$ Altogether, we have demonstrated resveratrol's antitumorigenic modulation of AKT and p53 in glioblastoma, in agreement with other groups. However, the extensive repertoire of resveratrol's antitumorigenic cellular and molecular mechanisms was not tested in this study, and such additional mechanisms also probably contribute to the anti-GBM effects observed.

Although resveratrol has repeatedly demonstrated positive antitumorigenic effects across a broad range of cancer types, its translation to clinical use has been challenging due to pharmacological and pharmacokinetic difficulties. $^{49}$ In mouse xenografts, resveratrol significantly suppressed GBM growth via oral administration and could ablate tumors while sparing normal tissue via intra- and peritumoral injection. Resveratrol is rapidly metabolized in vivo to produce adducts that possess significantly less potent anticancer properties, and achieving efficacious intratumoral concentrations of active resveratrol after oral administration is difficult. ${ }^{15}$ Similarly to a previously reported study for neuroblastoma, ${ }^{51}$ oral administration of resveratrol significantly suppressed GBM growth in vivo 
(Fig. 5) but did not cause tumor regression, presumably because intratumoral concentrations were insufficient to activate apoptotic mechanisms in GBM cells. Direct injection of resveratrol, a method reported to increase resveratrol concentration in xenograft models 1000 -fold, ${ }^{27}$ exhibited a stronger antitumor effect than oral delivery and almost completely halted tumor growth with no observed toxicity to surrounding normal tissue. To overcome biodistribution issues in humans, direct injection or CED could be used for therapeutic delivery to brain tumors. ${ }^{2,17}$ This is supported by our preliminary pharmacokinetic studies in normal brain (Table 1), which showed that direct delivery achieved 100-fold higher concentrations of local resveratrol, with longer duration. In addition to the direct injection of resveratrol as a therapeutic agent, or its combination with temozolomide, we are pursuing the development of novel resveratrol-based analogs that remain safe and effective and are designed with new features to improve solubility, achieve more efficient and effective intravenous delivery, reduce first-pass metabolism, and enhance bioavailability.

\section{Conclusions}

We have demonstrated widespread inhibitory effects of resveratrol against GBM cells and GSCs, as well as in vivo growth suppression of GBM through multiple administration routes. Resveratrol's nontoxic profile and broad anti-GBM effects strongly support its further development as an adjuvant therapy to improve patient outcomes, especially through its direct delivery.

\section{Acknowledgments}

This research was supported by NIH grants R21CA161704, P30 EY016665, T32GM007507, UL1RR025011, NCI HHSN2612 01000130C, and P30CA014520. We also appreciate support from the Wisconsin Partnership Program core grant to the Center for Stem Cell and Regenerative Medicine, the University of Wisconsin (Graduate School, School of Medicine and Public Health, and Department of Neurological Surgery), Research to Prevent Blindness, and the Retina Research Foundation (RRF). Drs. Kuo and Clark were partially supported by NIH grants R01NS75995 and R01CA158800, the Headrush Brain Tumor Research Professorship award, and the Roger Loff Memorial Fund for GBM Research. Dr. Polans is the RRF Kathryn and Latimer Murfee Chair.

\section{References}

1. Aggarwal BB, Bhardwaj A, Aggarwal RS, Seeram NP, Shishodia S, Takada Y: Role of resveratrol in prevention and therapy of cancer: preclinical and clinical studies. Anticancer Res 24:2783-2840, 2004

2. Alrfaei BM, Vemuganti R, Kuo JS: microRNA-100 targets SMRT/NCOR2, reduces proliferation, and improves survival in glioblastoma animal models. PLoS One 8:e80865, 2013

3. American Cancer Society: Cancer Facts and Figures 2009. Atlanta: American Cancer Society, 2009

4. Athar M, Back JH, Kopelovich L, Bickers DR, Kim AL: Multiple molecular targets of resveratrol: Anti-carcinogenic mechanisms. Arch Biochem Biophys 486:95-102, 2009

5. Bai RY, Staedtke V, Riggins GJ: Molecular targeting of glioblastoma: Drug discovery and therapies. Trends Mol Med 17:301-312, 2011

6. Bao S, Wu Q, McLendon RE, Hao Y, Shi Q, Hjelmeland $\mathrm{AB}$, et al: Glioma stem cells promote radioresistance by preferential activation of the DNA damage response. Nature 444:756-760, 2006

7. Barber TW, Brockway JA, Higgins LS: The density of tissues in and about the head. Acta Neurol Scand 46:85-92, 1970

8. Baur JA, Sinclair DA: Therapeutic potential of resveratrol: the in vivo evidence. Nat Rev Drug Discov 5:493-506, 2006

9. Bhattacharya S, Darjatmoko SR, Polans AS: Resveratrol modulates the malignant properties of cutaneous melanoma through changes in the activation and attenuation of the antiapoptotic protooncogenic protein Akt/PKB. Melanoma Res 21:180-187, 2011

10. Boocock DJ, Faust GE, Patel KR, Schinas AM, Brown VA, Ducharme MP, et al: Phase I dose escalation pharmacokinetic study in healthy volunteers of resveratrol, a potential cancer chemopreventive agent. Cancer Epidemiol Biomarkers Prev 16:1246-1252, 2007

11. Brennan CW, Verhaak RG, McKenna A, Campos B, Noushmehr H, Salama SR, et al: The somatic genomic landscape of glioblastoma. Cell 155:462-477, 2013

12. Cancer Genome Atlas Research Network: Comprehensive genomic characterization defines human glioblastoma genes and core pathways. Nature 455:1061-1068, 2008

13. Chen J, Li Y, Yu TS, McKay RM, Burns DK, Kernie SG, et al: A restricted cell population propagates glioblastoma growth after chemotherapy. Nature 488:522-526, 2012

14. Chin YR, Yuan X, Balk SP, Toker A: PTEN-deficient tumors depend on AKT2 for maintenance and survival. Cancer Discov 4:942-955, 2014

15. Chung JH, Manganiello V, Dyck JR: Resveratrol as a calorie restriction mimetic: therapeutic implications. Trends Cell Biol 22:546-554, 2012

16. Clark PA, Iida M, Treisman DM, Kalluri H, Ezhilan S, Zorniak M, et al: Activation of multiple ERBB family receptors mediates glioblastoma cancer stem-like cell resistance to EGFR-targeted inhibition. Neoplasia 14:420-428, 2012

17. Debinski W, Tatter SB: Convection-enhanced delivery for the treatment of brain tumors. Expert Rev Neurother 9:15191527,2009

18. Eyler CE, Foo WC, LaFiura KM, McLendon RE, Hjelmeland AB, Rich JN: Brain cancer stem cells display preferential sensitivity to Akt inhibition. Stem Cells 26:3027-3036, 2008

19. Filippi-Chiela EC, Thomé MP, Bueno e Silva MM, Pelegrini AL, Ledur PF, Garicochea B, et al: Resveratrol abrogates the temozolomide-induced G2 arrest leading to mitotic catastrophe and reinforces the temozolomide-induced senescence in glioma cells. BMC Cancer 13:147, 2013

20. Gagliano N, Aldini G, Colombo G, Rossi R, Colombo R, Gioia M, et al: The potential of resveratrol against human gliomas. Anticancer Drugs 21:140-150, 2010

21. Gallia GL, Tyler BM, Hann CL, Siu IM, Giranda VL, Vescovi AL, et al: Inhibition of Akt inhibits growth of glioblastoma and glioblastoma stem-like cells. Mol Cancer Ther 8:386-393, 2009

22. Gescher A, Steward WP, Brown K: Resveratrol in the management of human cancer: how strong is the clinical evidence? Ann N Y Acad Sci 1290:12-20, 2013

23. Günther HS, Schmidt NO, Phillips HS, Kemming D, Kharbanda S, Soriano R, et al: Glioblastoma-derived stem cell-enriched cultures form distinct subgroups according to molecular and phenotypic criteria. Oncogene 27:2897-2909, 2008

24. Guo D, Prins RM, Dang J, Kuga D, Iwanami A, Soto H, et al: EGFR signaling through an Akt-SREBP-1-dependent, rapamycin-resistant pathway sensitizes glioblastomas to antilipogenic therapy. Sci Signal 2:ra82, 2009

25. Jiang H, Shang X, Wu H, Gautam SC, Al-Holou S, Li C, et al: Resveratrol downregulates PI3K/Akt/mTOR signaling pathways in human U251 glioma cells. J Exp Ther Oncol 8:25-33, 2009 
26. Jiang H, Shang X, Wu H, Huang G, Wang Y, Al-Holou S, et al: Combination treatment with resveratrol and sulforaphane induces apoptosis in human U251 glioma cells. Neurochem Res 35:152-161, 2010

27. Kenealey JD, Subramanian L, Van Ginkel PR, Darjatmoko S Lindstrom MJ, Somoza V, et al: Resveratrol metabolites do not elicit early pro-apoptotic mechanisms in neuroblastoma cells. J Agric Food Chem 59:4979-4986, 2011

28. Kim TM, Huang W, Park R, Park PJ, Johnson MD: A developmental taxonomy of glioblastoma defined and maintained by MicroRNAs. Cancer Res 71:3387-3399, 2011

29. Kma L: Synergistic effect of resveratrol and radiotherapy in control of cancers. Asian Pac J Cancer Prev 14:6197-6208, 2013

30. Liu G, Yuan X, Zeng Z, Tunici P, Ng H, Abdulkadir IR, et al: Analysis of gene expression and chemoresistance of CD133+ cancer stem cells in glioblastoma. Mol Cancer 5:67, 2006

31. Lu KH, Chen YW, Tsai PH, Tsai ML, Lee YY, Chiang CY, et al: Evaluation of radiotherapy effect in resveratrol-treated medulloblastoma cancer stem-like cells. Childs Nerv Syst 25:543-550, 2009

32. Mangiola A, de Bonis P, Maira G, Balducci M, Sica G, Lama $\mathrm{G}$, et al: Invasive tumor cells and prognosis in a selected population of patients with glioblastoma multiforme. Cancer 113:841-846, 2008

33. Miranpuri G, Hinchman A, Wang A, Schomberg D, Kubota $\mathrm{K}$, Brady M, et al: Convection enhanced delivery: a comparison of infusion characteristics in ex vivo and in vivo nonhuman primate brain tissue. Ann Neurosci 20:108-114, 2013

34. Molina JR, Hayashi Y, Stephens C, Georgescu MM: Invasive glioblastoma cells acquire stemness and increased Akt activation. Neoplasia 12:453-463, 2010

35. Mure H, Matsuzaki K, Kitazato KT, Mizobuchi Y, Kuwayama K, Kageji T, et al: Akt2 and Akt3 play a pivotal role in malignant gliomas. Neuro Oncol 12:221-232, 2010

36. Noushmehr H, Weisenberger DJ, Diefes K, Phillips HS, Pujara $\mathrm{K}$, Berman BP, et al: Identification of a $\mathrm{CpG}$ island methylator phenotype that defines a distinct subgroup of glioma. Cancer Cell 17:510-522, 2010

37. Pangeni R, Sahni JK, Ali J, Sharma S, Baboota S: Resveratrol: review on therapeutic potential and recent advances in drug delivery. Expert Opin Drug Deliv 11:1285-1298, 2014

38. Park JW, Woo KJ, Lee JT, Lim JH, Lee TJ, Kim SH, et al: Resveratrol induces pro-apoptotic endoplasmic reticulum stress in human colon cancer cells. Oncol Rep 18:12691273,2007

39. Parsons DW, Jones S, Zhang X, Lin JC, Leary RJ, Angenendt $\mathrm{P}$, et al: An integrated genomic analysis of human glioblastoma multiforme. Science 321:1807-1812, 2008

40. Patel KR, Brown VA, Jones DJ, Britton RG, Hemingway D, Miller AS, et al: Clinical pharmacology of resveratrol and its metabolites in colorectal cancer patients. Cancer Res 70:7392-7399, 2010

41. Phillips HS, Kharbanda S, Chen R, Forrest WF, Soriano RH, Wu TD, et al: Molecular subclasses of high-grade glioma predict prognosis, delineate a pattern of disease progression, and resemble stages in neurogenesis. Cancer Cell 9:157-173, 2006

42. Pistollato F, Bremer-Hoffmann S, Basso G, Cano SS, Elio I, Vergara MM, et al: Targeting glioblastoma with the use of phytocompounds and nanoparticles. Target Oncol 11:1-16, 2016

43. Sareen D, Darjatmoko SR, Albert DM, Polans AS: Mitochondria, calcium, and calpain are key mediators of resveratrol-induced apoptosis in breast cancer. Mol Pharmacol 72:1466-1475, 2007

44. Sato A, Okada M, Shibuya K, Watanabe E, Seino S, Suzuki $\mathrm{K}$, et al: Resveratrol promotes proteasome-dependent degradation of Nanog via p53 activation and induces differentia- tion of glioma stem cells. Stem Cell Res (Amst) 11:601-610, 2013

45. Shakibaei M, Harikumar KB, Aggarwal BB: Resveratrol addiction: to die or not to die. Mol Nutr Food Res 53:115-128, 2009

46. Shu XH, Li H, Sun XX, Wang Q, Sun Z, Wu ML, et al: Metabolic patterns and biotransformation activities of resveratrol in human glioblastoma cells: relevance with therapeutic efficacies. PLoS One 6:e27484, 2011

47. Singh SK, Hawkins C, Clarke ID, Squire JA, Bayani J, Hide $\mathrm{T}$, et al: Identification of human brain tumour initiating cells. Nature 432:396-401, 2004

48. Stupp R, Mason WP, van den Bent MJ, Weller M, Fisher $\mathrm{B}$, Taphoorn MJ, et al: Radiotherapy plus concomitant and adjuvant temozolomide for glioblastoma. $\mathbf{N}$ Engl J Med 352:987-996, 2005

49. Subramanian L, Youssef S, Bhattacharya S, Kenealey J, Polans AS, van Ginkel PR: Resveratrol: challenges in translation to the clinic - a critical discussion. Clin Cancer Res 16:5942-5948, 2010

50. van Ginkel PR, Darjatmoko SR, Sareen D, Subramanian L, Bhattacharya S, Lindstrom MJ, et al: Resveratrol inhibits uveal melanoma tumor growth via early mitochondrial dysfunction. Invest Ophthalmol Vis Sci 49:1299-1306, 2008

51. van Ginkel PR, Sareen D, Subramanian L, Walker Q, Darjatmoko SR, Lindstrom MJ, et al: Resveratrol inhibits tumor growth of human neuroblastoma and mediates apoptosis by directly targeting mitochondria. Clin Cancer Res 13:51625169,2007

52. Verhaak RG, Hoadley KA, Purdom E, Wang V, Qi Y, Wilkerson MD, et al: Integrated genomic analysis identifies clinically relevant subtypes of glioblastoma characterized by abnormalities in PDGFRA, IDH1, EGFR, and NF1. Cancer Cell 17:98-110, 2010

53. Vogelbaum MA, Aghi MK: Convection-enhanced delivery for the treatment of glioblastoma. Neuro Oncol 17 (Suppl 2):ii3-ii8, 2015

54. Wakimoto H, Mohapatra G, Kanai R, Curry WT Jr, Yip S, Nitta M, et al: Maintenance of primary tumor phenotype and genotype in glioblastoma stem cells. Neuro Oncol 14:132144,2012

55. Walle T, Hsieh F, DeLegge MH, Oatis JE Jr, Walle UK: High absorption but very low bioavailability of oral resveratrol in humans. Drug Metab Dispos 32:1377-1382, 2004

56. Wang Q, Xu J, Rottinghaus GE, Simonyi A, Lubahn D, Sun GY, et al: Resveratrol protects against global cerebral ischemic injury in gerbils. Brain Res 958:439-447, 2002

57. Wenzel E, Somoza V: Metabolism and bioavailability of trans-resveratrol. Mol Nutr Food Res 49:472-481, 2005

58. Yan H, Parsons DW, Jin G, McLendon R, Rasheed BA, Yuan W, et al: IDH1 and IDH2 mutations in gliomas. N Engl J Med 360:765-773, 2009

59. Yang YP, Chang YL, Huang PI, Chiou GY, Tseng LM, Chiou SH, et al: Resveratrol suppresses tumorigenicity and enhances radiosensitivity in primary glioblastoma tumor initiating cells by inhibiting the STAT3 axis. J Cell Physiol 227:976-993, 2012

60. Zorniak M, Clark PA, Leeper HE, Tipping MD, Francis DM, Kozak KR, et al: Differential expression of 2',3'-cyclicnucleotide 3'-phosphodiesterase and neural lineage markers correlate with glioblastoma xenograft infiltration and patient survival. Clin Cancer Res 18:3628-3636, 2012

\section{Disclosures}

The authors report no conflict of interest concerning the materials or methods used in this study or the findings specified in this paper. 


\section{Author Contributions}

Conception and design: Kuo, Clark, Bhattacharya, van Ginkel, Polans. Acquisition of data: Clark, Bhattacharya, Elmayan, Darjatmoko, Thuro, Yan, van Ginkel. Analysis and interpretation of data: Kuo, Clark, Bhattacharya, van Ginkel, Polans. Drafting the article: Clark, Bhattacharya, van Ginkel. Critically revising the article: Kuo, Clark, Bhattacharya, van Ginkel, Polans. Reviewed submitted version of manuscript: all authors. Approved the final version of the manuscript on behalf of all authors: Kuo. Statistical analysis: Clark, Bhattacharya, van Ginkel. Study supervision: Kuo, Polans.

\section{Supplemental Information}

Previous Presentations

Portions of this work were presented at the 2014 Society for Neuro-oncology Annual Meeting (November 13-16, Miami, Florida) and the 2015 AANS Annual Meeting (May 2-6, Washington, DC).

\section{Correspondence}

John S. Kuo, Department of Neurological Surgery, School of Medicine and Public Health, Box 8660 Clinical Science Center, 600 Highland Ave., Madison, WI 53792-8660. email: j.kuo@ neurosurgery.wisc.edu. 